\title{
Coriolis Meter Density Errors Induced by Ambient Air and Fluid Temperature Differentials
}

\author{
Gordon Lindsay, TÜV SÜD National Engineering Laboratory, Coventry University \\ Norman Glen, TÜV SÜD National Engineering Laboratory \\ John Hay, TÜV SÜD National Engineering Laboratory \\ Seyed Shariatipour, Coventry University \\ Manus Henry, University of Oxford, Coventry University, South Ural State University
}

\begin{abstract}
Coriolis metering technology is widely applied throughout industry. In addition to the mass flow rate, a Coriolis meter can measure fluid density based on the resonant frequency of the flow tube vibration. There is currently increasing interest in utilising this density measurement capability as the primary process value in applications such as precision control for fluid property conditioning, and fluid contamination monitoring.

However, within these applications, ambient temperature variation can be significant.

This paper details research data obtained using NEL's 'Very Low Flow' single-phase facility. The rig was modified to include a programmable temperature enclosure in which a Coriolis meter was installed. Two commercial meter models from the same manufacturer were tested. Both meters showed fluid density errors when subjected to fluctuations in the surrounding ambient air temperature. The fluid properties of the test medium were confirmed to be stable using NEL's UKAS standard reference instrumentation.

Previous temperature effects research for Coriolis meters have focussed on the process fluid temperature and there is little published data on the effects of ambient temperature.
\end{abstract}

\section{INTRODUCTION}

The continued development of Coriolis flow metering technology has been well documented and summarised in [1], [2] and [3]. During the evolution of this technology, a largely consistent device design has emerged. While manufacturer and application-specific variations exist, the common design principle entails a single or dual flow tube, which is manufactured in either a straight or curved configuration. The flow tube is mechanically driven to oscillate at its natural frequency. Displacement (or more usually velocity) sensors located upstream and downstream of the centre of the flow tube are used to determine the extent of Coriolis force exerting twist. The time delay measured by these sensors is proportional to the mass flow rate passing through the meter. If no mass flow is present there will be no Coriolis force, and therefore no time delay is detected between the upstream and downstream sensors.

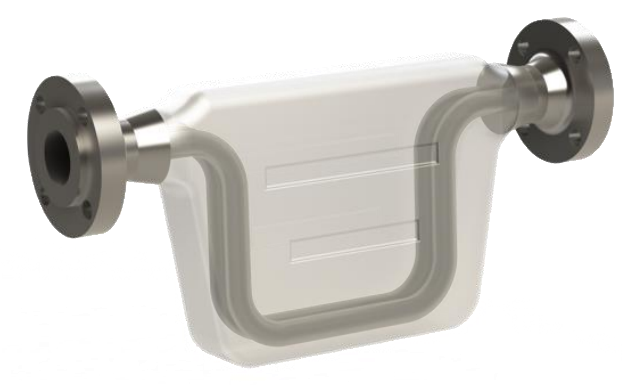

Fig. 1 - Typical Coriolis Mass Flow Meter Structure

As a secondary output, a Coriolis meter is also capable of determining the density of the fluid present within the vibrating pipe sections. This process value is determined from the resonant frequency of the flow tube and is defined in [4] as

$$
\begin{aligned}
& f_{r f}=(1 / 2 \pi) \cdot(C / m)^{1 / 2} \\
& m=m_{t b}+m_{f} \\
& m_{f}=\left(\rho_{f}\right) \cdot\left(V_{f}\right)
\end{aligned}
$$

Where

- $f_{r f}$ is the resonant frequency

- $\quad$ is the mechanical stiffness/spring constant

- $m$ is the total mass

- $m_{t b}$ is the mass of the oscillating flow tube 
- $\quad m_{f} \quad$ is the mass of fluid within the oscillating flow tube

- $\quad V_{f} \quad$ is the volume of fluid within the oscillating flow tube

- $\quad \rho_{f} \quad$ is the density of the fluid

To calculate the density of the fluid within the flow tube, the following equation can be derived from equations 1, 2 and 3:

$$
\rho_{f}=\left\{\frac{c}{\left[V_{f}\left(2 \pi f_{r f}\right)^{2}\right]}\right\}-m_{t b} / m_{f}
$$

The phenomenon of ambient air temperature affecting the quality of Coriolis meter measurements has been noted in earlier research. In [5], an examination of 'zero drift' highlighted ambient temperature variation as a contributing factor. In [6], where the suitability of Coriolis technology was assessed for a specific industrial application, it was again observed that ambient air fluctuations, which were intentionally introduced into the system by the research team, caused a detectable drift in the meter mass flow rate.

It should be noted that [5] and [6] do not address the effects of ambient air temperature on the fluid density output from Coriolis meters. It is this gap in knowledge that this research intends to address.

The diagnostic capabilities of Coriolis transmitters which are responsible for analogue signal interpretation, digitisation and process value correction have been discussed previously [7]. Significant research has also been conducted with respect to developing the capabilities of the transmitter. In particular, the research described in [8] developed a self-validating sensor, capable of fault detection and data correction to ensure measurement quality is upheld.

An initial investigation into the effects of air temperature on the density measurement from a Coriolis flow meter is reported in [9].

The results in [9] were presented to a Coriolis manufacturer and a partnership was formed, the research objective being to develop a new temperature correction model that would significantly reduce errors and which could readily be implemented in a conventional commercial transmitter [10], [11].

Correct measurement and interpretation of data output from flow metering technologies is key to production forecasting, custody transfer and fiscal metering [12], [13], [14], [15], [16].

\section{TEST DESIGN}

To ensure fine control over all variables, NEL's Very Low Flow Facility (VLFF) was used. The $8 \mathrm{~mm}$ pipe bore supports good temperature control on a minimised mass of fluid, compared to NEL's larger flow loops. The VLFF is housed in a small ( $4 \mathrm{~m} \times 3 \mathrm{~m} \times 2 \mathrm{~m}$ ) laboratory, reducing the potential for uncontrolled ambient temperature fluctuation. Details of the VLFF and the test matrix are described in sections 2.1 and 2.2.

\subsection{Facility Layout and Equipment}

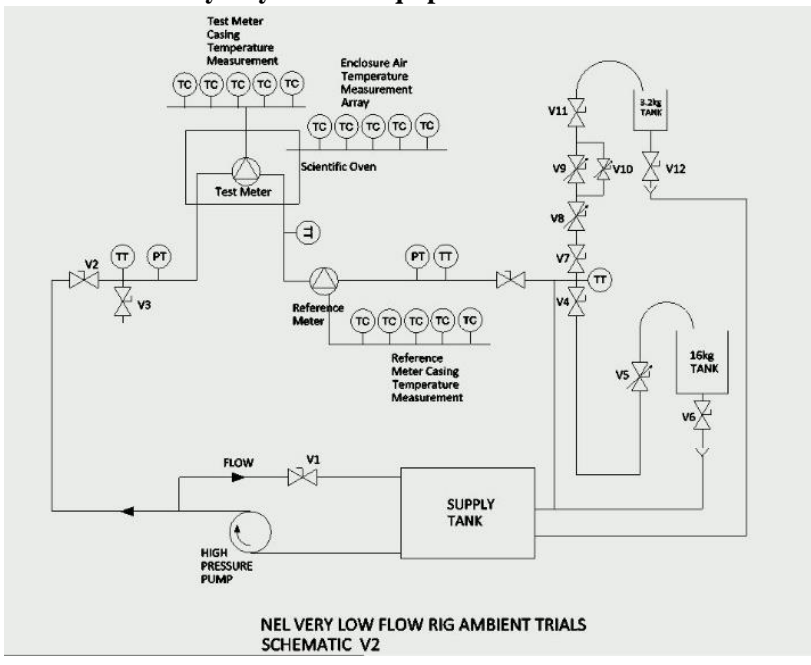

Fig. 2 - VLFF setup and Instrumentation Overview, where: - TT is Temperature Transmitter, PT is Pressure Transmitter and TC is Thermocouple

The VLFF (Fig. 2) was modified so that the test section pipework passed through an environmental enclosure. Within this enclosure, a $6 \mathrm{~mm}$ dual tube, curved Coriolis mass flow meter (the 'test' meter) was installed and connected to the test section pipework. Downstream of the test meter/temperature enclosure, an identical Coriolis meter (the 'reference' meter) was installed in series, but kept at an ambient temperature of approximately $20^{\circ} \mathrm{C}$. Note that the transmitters for both meters were installed in the ambient temperature region the investigation considered only temperature effects on the test flow tube, not on its transmitter. The reference meter served as a live comparison on the test meter performance during experimentation. Traceable reference measurements for fluid density and temperature were provided using NEL's reference instrumentation and analysis procedures. To monitor for any change in fluid properties due to heat exchange from the circulation pump, the temperature enclosure, or the test meter body at an elevated temperature, reference platinum resistance thermometers (PRTs) were installed in key locations throughout the loop. The PRTs were calibrated in NEL's UKAS accredited temperature calibration laboratory, and the resulting polynomial curves programmed into the data acquisition software. The measurement uncertainty of each probe was $\pm 0.02^{\circ} \mathrm{C}$. Fluid temperature variations were monitored and their impact on fluid density calculated.

The VLFF was run in recirculation mode. The experimental configuration is identical to that used in the initial research phase described in [9].

In this paper, two meter models from the same manufacturer were characterised; these are referred to as Meter A and Meter B. Both meter designs were of comparable sizing and flow rate specifications. Meter A is the manufacturer's current generation of commercial product. Meter B is a prototype of a future product, designed to improve measurement performance and improve its sensitivity to flow conditions by reducing the mass of the flow tube and supporting structural components. Both meters, however, use the same temperature compensation equations and have the same 
number of temperature sensors attached to the meter body, in comparable locations.

To fully understand the effects of ambient temperature fluctuation on the metering technology, access was granted by the manufacturer to the raw process values as well as the meter specific temperature compensation algorithms implemented in the transmitter. This provided evidence of how the meters physically respond to the test conditions as well as allowing an assessment of the current temperature compensation algorithms.

Data was polled via Modbus from the reference and test meters every second.

The manufacturer's compensation algorithms were deactivated on both meters so that only the raw process values were logged. Compensation was then applied to the raw data time series from each instrument during off-line data analysis.

The reference density values for water and kerosene were obtained via fluid sampling and analysis by NEL's UKAS accredited laboratories over the temperature range $5^{\circ} \mathrm{C}$ to $55^{\circ} \mathrm{C}$. All density errors reported in this paper are with respect to these reference values.

\subsection{Test Procedure}

While the fluid flow rate was shown to influence the density error in our previous work [9], here initial trials indicated that the reported density is not sensitive to flow rate change at elevated ambient temperatures. Therefore, mass flow rates were kept constant throughout the tests, specifically at a rate which minimised fluid residency time in the temperature enclosure.

Tests were carried out on the two meter designs using water and kerosene as process fluids, where the environmental temperature was varied between $20^{\circ} \mathrm{C}$ and $60^{\circ} \mathrm{C}$. Tables 1 and 2 provide the experimental conditions examined, while the results are described in sections 3 and 4.

Table 1 - Meters A and B - Stepped Ambient Air Temperature Variation
Test Parameters

\begin{tabular}{|c|c|c|c|c|c|c|c|c|}
\hline $\begin{array}{l}\text { Test } \\
\text { No }\end{array}$ & Fluid & $\begin{array}{c}\text { Highest } \\
\text { Fluid Flow } \\
\text { Rate } \\
\text { (kg/hr) }\end{array}$ & $\begin{array}{c}\text { Initial } \\
\text { Test } \\
\text { Meter } \\
\text { Air } \\
\text { Temp } \\
\text { (C) }\end{array}$ & $\begin{array}{c}\text { Final } \\
\text { Test } \\
\text { Meter } \\
\text { Air } \\
\text { Temp } \\
\text { (C) }\end{array}$ & $\begin{array}{c}\text { Rate of } \\
\text { Test Meter } \\
\text { Air Temp } \\
\text { Changer } \\
\text { ('C) }\end{array}$ & $\begin{array}{c}\text { Reference } \\
\text { Meter AAr } \\
\text { Temp } \\
\text { Setpoiint } \\
\text { (C) }\end{array}$ & $\begin{array}{c}\text { Fluid } \\
\text { Temp } \\
\text { Setpoint } \\
\text { (C) }\end{array}$ & $\begin{array}{c}\text { Test } \\
\text { Duration } \\
\text { (Hrs) }\end{array}$ \\
\hline 1 & Water & 230 & 20 & 60 & $10 / 60$ mins & 20 & 20 & 8 \\
\hline 2 & Kerosene & 230 & 20 & 60 & $10 / 60$ mins & 20 & 20 & 8 \\
\hline
\end{tabular}

Table 2 - Meter B - Extreme Fluctuation Parameters

\begin{tabular}{|c|c|c|c|c|c|c|c|c|c|}
\hline Fluid & $\begin{array}{l}\text { Highest } \\
\text { Flid } \\
\text { Flow } \\
\text { Rate } \\
\text { (kkghr) }\end{array}$ & $\begin{array}{l}\text { Lowest } \\
\text { Fluid } \\
\text { Fol } \\
\text { Rate } \\
(\mathrm{kg} / \mathrm{hr})\end{array}$ & 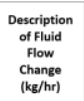 & 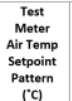 & 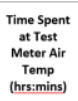 & 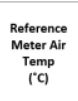 & 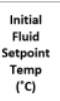 & $\begin{array}{c}\text { Final } \\
\text { fFulid } \\
\text { Setpoint } \\
\text { Tomp } \\
\text { (c) }\end{array}$ & 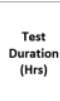 \\
\hline Kerossene & 82 & 82 & $\mathrm{~N} / \mathrm{A}$ & $\begin{array}{c}20,30, \\
40,50, \\
60\end{array}$ & $\begin{array}{c}1: 00,1: 00, \\
1: 00,1: 00, \\
1: 00\end{array}$ & 20 & 13 & 15 & 5 \\
\hline
\end{tabular}

For tests 1 and 2, before data collection was undertaken, the fluid was circulated through the VLFF for a period of one hour to ensure steady-state conditions were achieved. During this time the chamber door was open to ensure both the reference and test meters were exposed to the same air temperature. Once steady-state conditions were established, the data acquisition system was started. For the initial $20^{\circ} \mathrm{C}$ air temperature setpoint, the enclosure door remained open to ensure a true baseline air temperature was logged for both the reference and test meters. At the end of tests 1 and 2 the enclosure door was opened, while the fluid continued to circulate, in order to observe the effect of 'rapid' ambient cooling. The focus of this paper is the fluid density values generated by the meter. The performance of other meter process variables (e.g. mass flow and temperature) are reported in [17].

\section{METER A RESULTS}

\subsection{Reference Measurements and Data Analysis}

Figs. 3. and 4. show the test meter's ambient air temperature changes as measured by the enclosure thermocouple (Fig. 2) for tests 1 and 2 respectively. The reference fluid temperature as measured by the test section central PRT (Fig. 2) is also trended. The reference fluid temperature increased by $1^{\circ} \mathrm{C}$ and $0.8^{\circ} \mathrm{C}$ for water and kerosene respectively.

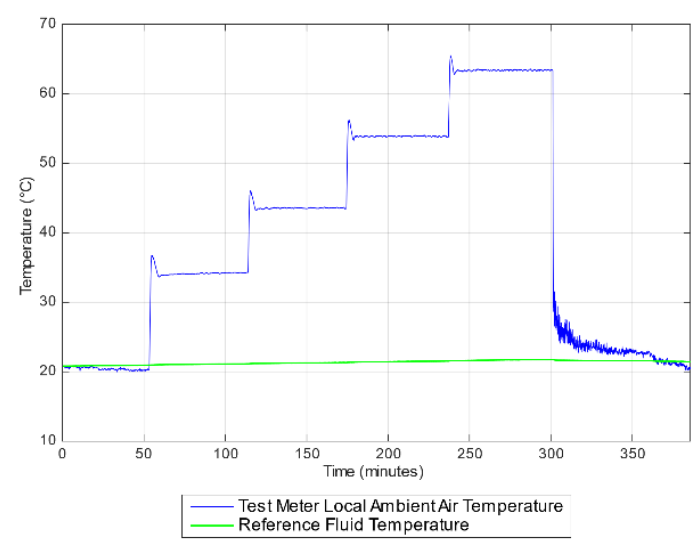

Fig. 3 - Test Meter Ambient Air Temperature \& Reference Fluid Temperature (Water)

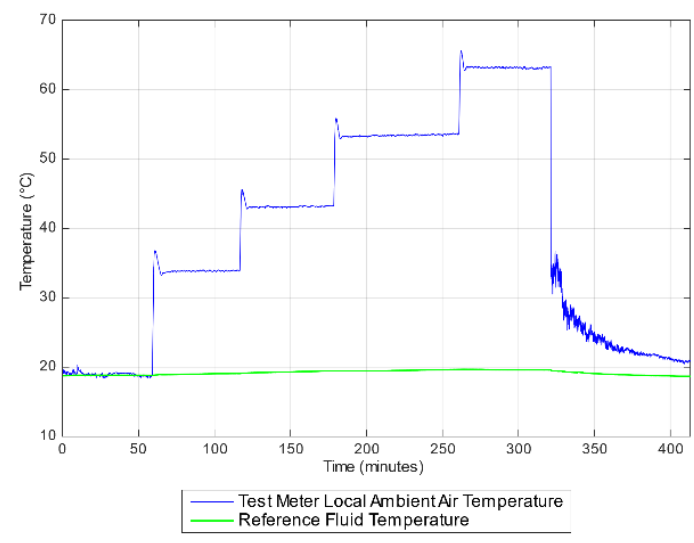

Fig. 4 - Test Meter Ambient Air Temperature \& Reference Fluid Temperature (Kerosene)

Fig. 5. and Fig. 6. show the corresponding room temperatures. The intention was to maintain the room temperature to within $\pm 1^{\circ} \mathrm{C}$ of its initial value. However, unseasonably warm weather caused variations of $+1^{\circ} \mathrm{C} /-$ $4^{\circ} \mathrm{C}$ for the water trial and $+4.1^{\circ} \mathrm{C} /-1^{\circ} \mathrm{C}$ for Kerosene. 


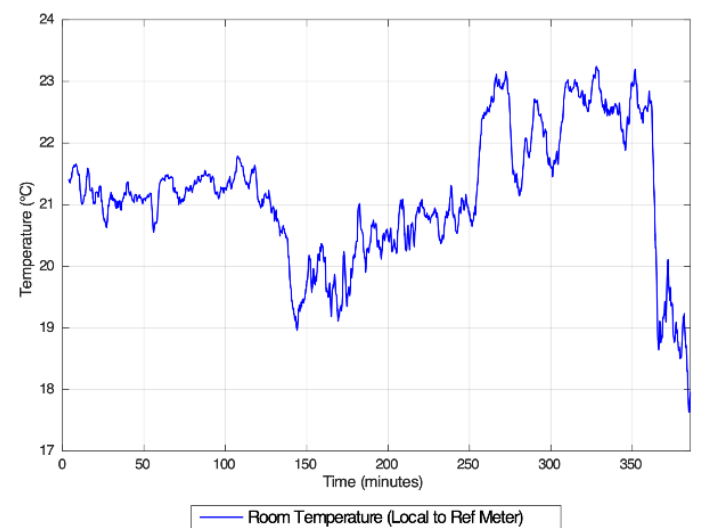

Fig. 5 - Room Temperature (Reference Meter Local Air Temperature) during Test 1

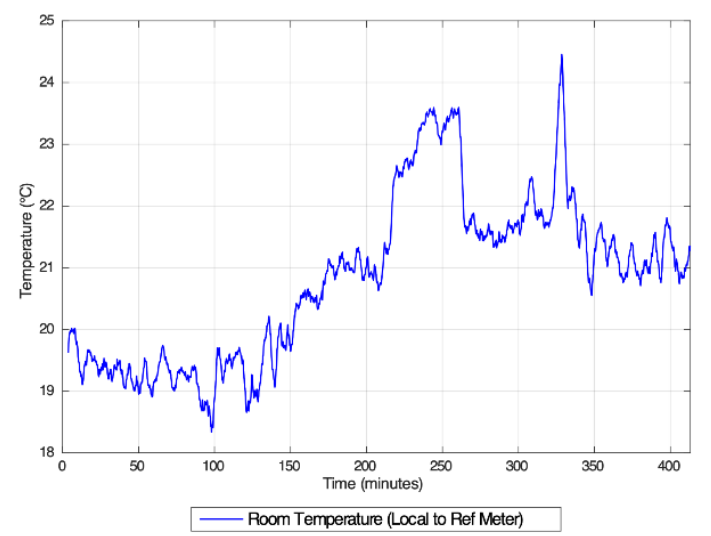

Fig. 6-Room Temperature (Reference Meter Local Air Temperature) during Test 2

Fig. 7 and Fig. 8 show the density of water and kerosene between $5^{\circ} \mathrm{C}$ and $55^{\circ} \mathrm{C}$. This data was generated from direct fluid samples and subsequent analysis in NEL's fluid property laboratory, with an uncertainty of $\pm 0.01 \mathrm{~kg} / \mathrm{m}^{3}$. This data was used for the determination of test meter density error for Meters A and B.

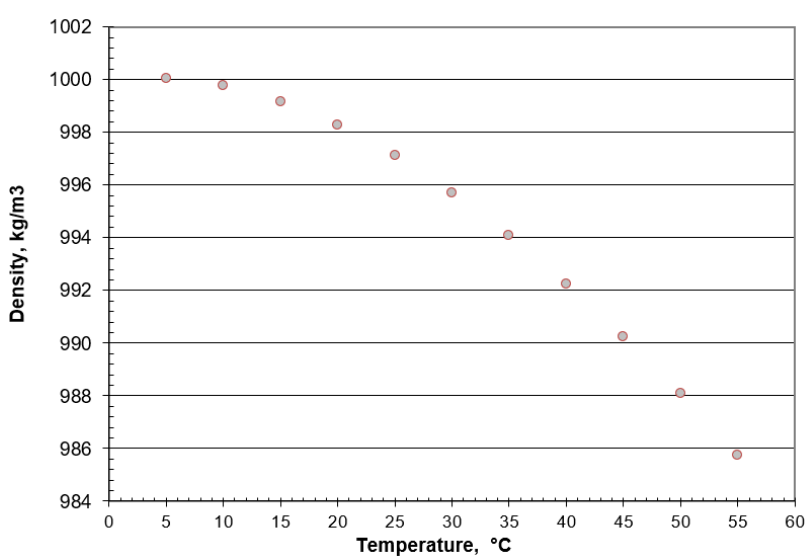

Fig. 7-Water Density

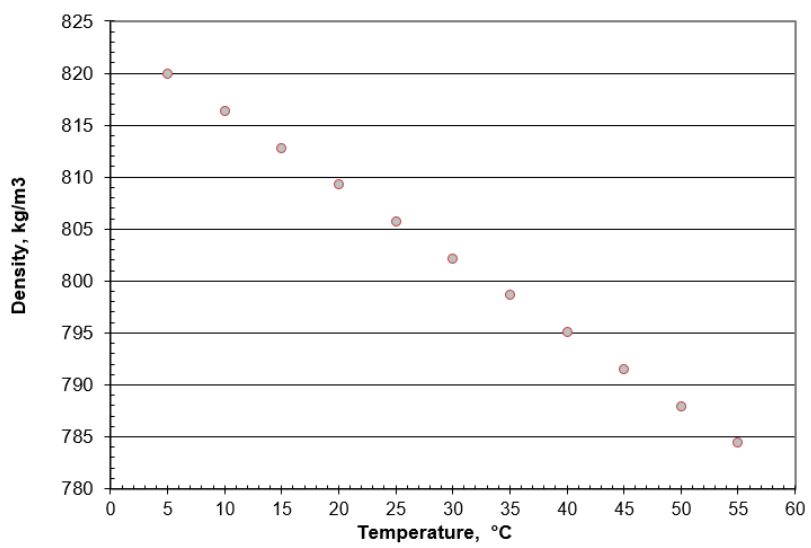

Fig. 8-Kerosene Density

\subsection{Meter Uncompensated Fluid Density Drift}

The uncompensated values for the reference and test meter densities are shown in Figs. 9. and 10.

Fig. 9. shows that for test 1 , the test meter density varied from $992 \mathrm{~kg} / \mathrm{m}^{3}$ to $1075 \mathrm{~kg} / \mathrm{m}^{3}$ due to ambient air heating (Fig. 3.) and therefore produced errors up to $+7.8 \%$. The reference meter fluid density followed the variations in room air temperature (Fig. 5.).

It should be noted that the uncompensated baseline density value reported by the reference meter had a $-1.1 \%$ error, while the test meter baseline density had a $-0.6 \%$ error (compare Fig. 7.).

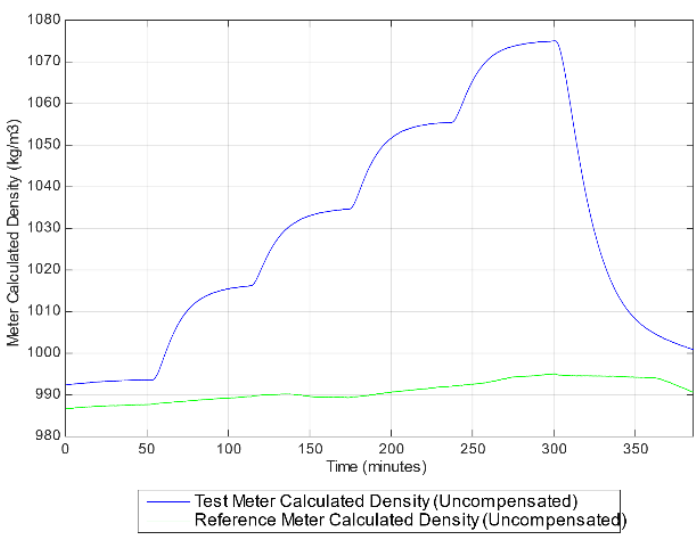

Fig. 9-Meter A, test and reference meter uncompensated density response (Water)

Similar patterns were observed in test 2. Fig. 10. shows a strong correlation between the ambient air temperature (Fig. 4.) and the uncompensated density value.

A change in test meter reported density from 786 $\mathrm{kg} / \mathrm{m}^{3}$ to $871 \mathrm{~kg} / \mathrm{m}^{3}$ was observed during the incremental heating stage of testing resulting in an error of $+7.8 \%$ at $63^{\circ} \mathrm{C}$ ambient. 


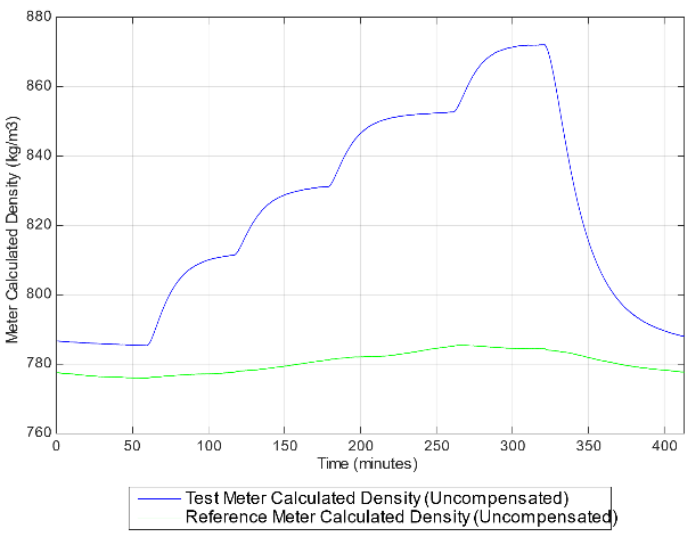

Fig. 10-Meter A test and reference meter uncompensated density response (Kerosene)

The magnitude of the errors described above are to be expected for non temperature compensated data. They are included in this paper to highlight the difference between uncompensated and compensated fluid density under the existing model described in 3.3.

\subsection{Compensated Density using current Manufacturer} algorithm

Fig. 11. and Fig. 12. show that when the temperature compensation algorithm is applied to the uncompensated data, the error is reduced. However, there is still a clear pattern that correlates with the air temperature changes. An error of $-0.42 \%$ is still present on the test meter at the maximum ambient air temperature tested (Fig. 3). The reference meter compensated fluid density is shown to correlate to room ambient conditions (Fig. 5)

It should be noted that an offset of $+0.08 \%$ is present for the reference meter when compared to the fluid properties curve (Fig. 7.).

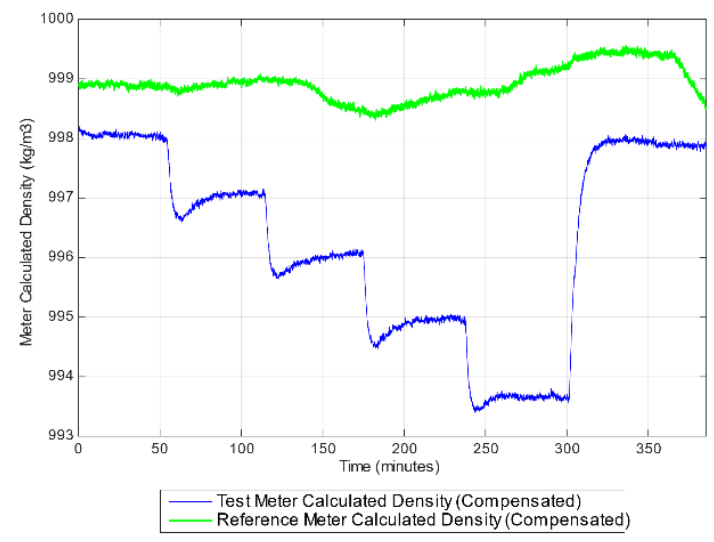

Fig. 11 -Meter A, test and reference meter temperature compensated, density response (Water)

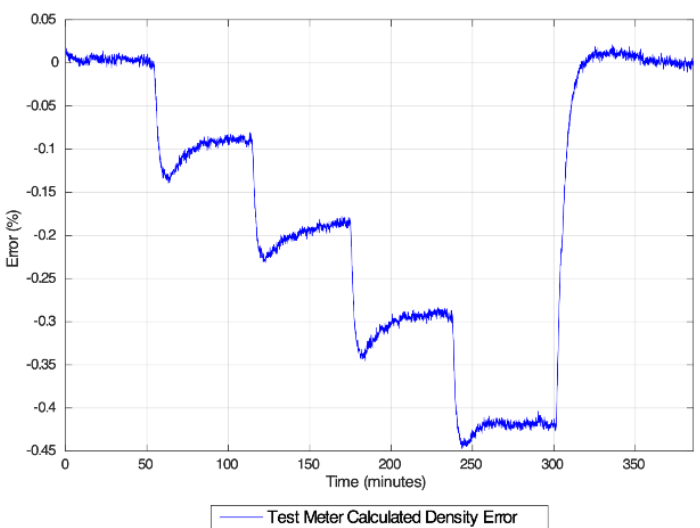

Fig. 12 - Meter A, test meter density error (Water)

The compensated data for test 2 shown in Fig. 13. and Fig. 14. show similar trends to test 1 . Here the test meter error reached a value of $-1.3 \%$ at the maximum ambient air temperature tested (Fig. 4).

The initial baseline value for the test meter was shown to contain a $-0.2 \%$ error from the known fluid property value (compare Fig. 4. and 8.) It should also be noted that the baseline error between the reference and test meter also increased to a value of $-0.4 \%$ with the reference meter showing $-0.6 \%$ error from known fluid properties.

The overall increase in errors highlights that the fluid density calculation and temperature compensation techniques currently implemented by the manufacturer are sensitive to fluid property changes.

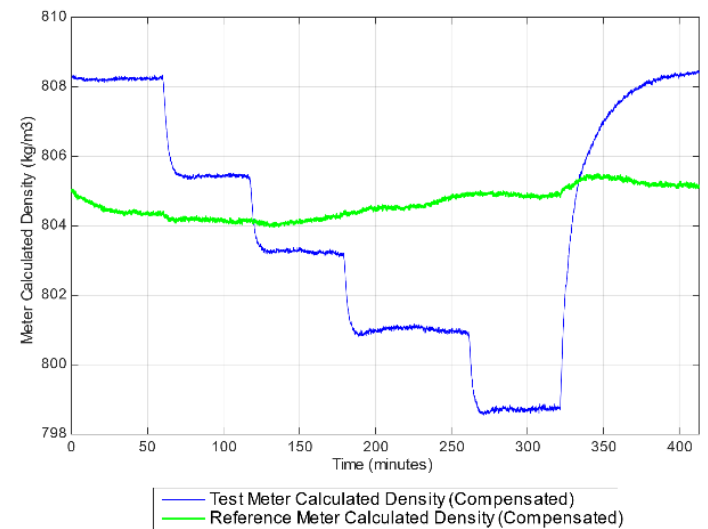

Fig. 13 - Meter A, test and reference meter temperature compensated, density response (Kerosene) 


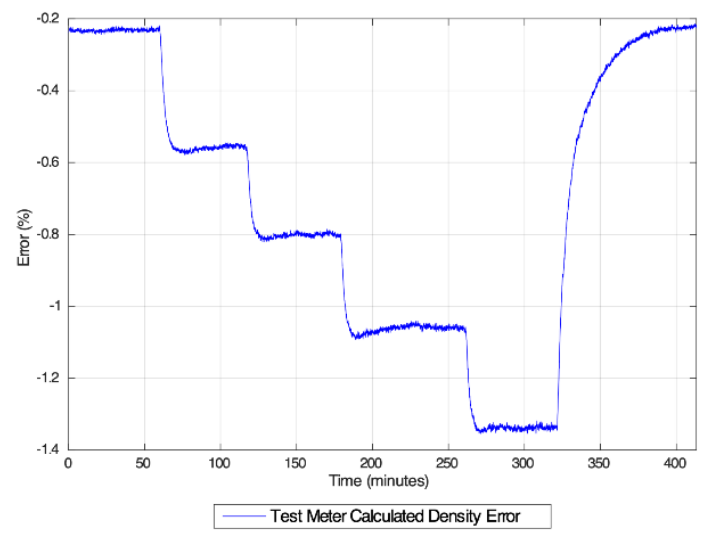

Fig. 14 - Meter A, test meter density error (Kerosene)

\section{METER B RESULTS}

The experiments of section 3 were repeated using a different meter model from the same manufacturer. In addition, this meter was exposed to extreme changes in ambient air temperature. This was designed to be representative of conditions that may be encountered in the field, such as sudden increases and decreases in air temperature due to sunlight. The results of these experiments are presented and discussed below.

\subsection{Stepped ambient air temperature.}

The temperature and flow conditions detailed in Fig.3 and Fig. 4 (Table 1) were recreated to evaluate Meter B's response. The test meter compensated density error for test 1 is shown in Fig. 15.

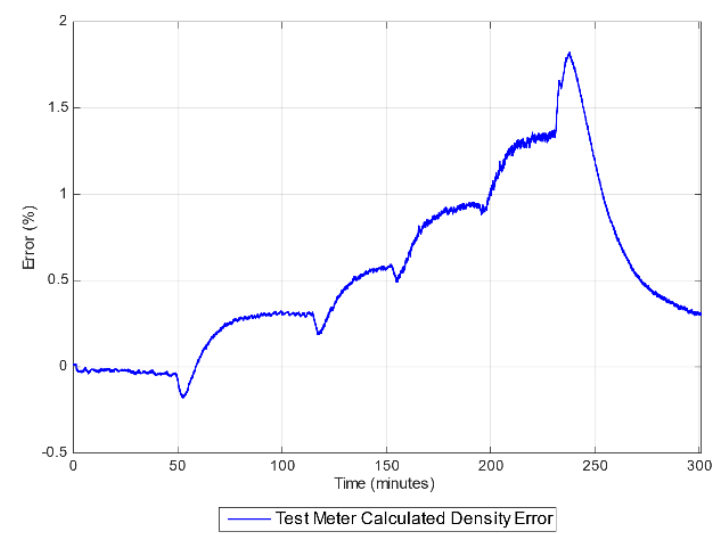

Fig. 15 -Meter B, test meter density error (Water)

As with Meter A, it was observed that the ambient air temperature changes induced errors in the test meter fluid density calculation, which correlate with the air temperature. Fig. 15 shows that an error of $+1.4 \%$ was observed at an ambient temperature of $63^{\circ} \mathrm{C}$ with a maximum value of $+1.75 \%$ observed during the cool down at the end of testing. It is noteworthy that the overall errors observed had a greater magnitude than that of Meter A (Fig. 12). In addition, the errors are usually positive and in general, the trend response with respect to the heating pattern has been dampened in Meter B.
The error induced in Meter B's compensated density output during test 2 is shown in Fig. 16.

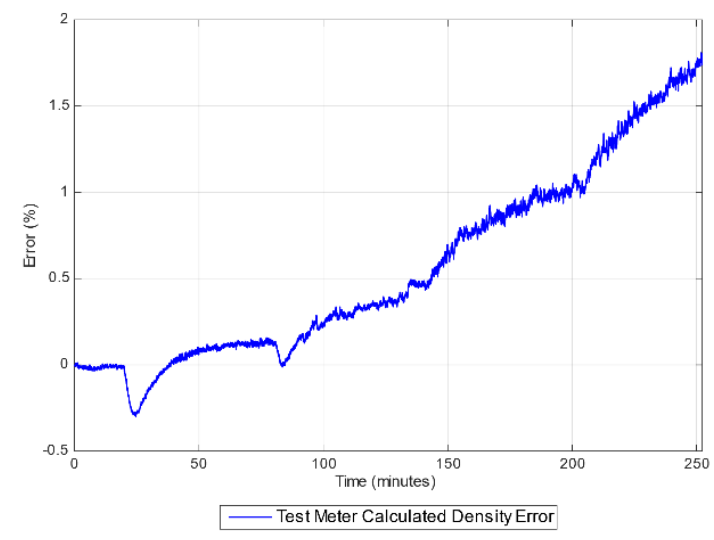

Fig. 16-Meter B test meter density error (Kerosene)

In this case for Meter B, the maximum error observed was comparable to that of water (approximately $+1.7 \%$ ). This is a notable contrast to Meter A's behaviour and shows that while the observed errors from Meter B are greater, they are more consistent for the two fluids tested. Furthermore, there is less clear correlation with ambient air temperature.

\subsection{Meter B - Extreme fluctuations.}

Additional experimentation was carried out to assess Meter B's density value response where the ambient air temperature was cycled between $25^{\circ} \mathrm{C}, 63^{\circ} \mathrm{C}$ and $43^{\circ} \mathrm{C}$ for varying durations of time. The reference temperature conditions for this test are shown in Fig. 17.

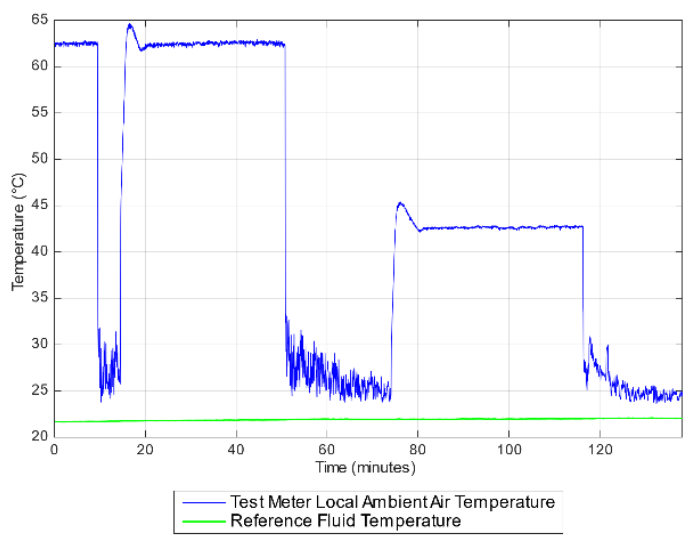

Fig. 17 - Test Meter Ambient Air Temperature \& Reference Fluid Temperature (Kerosene)

Fig.17. shows that the test commenced with a test meter ambient air temperature of $63^{\circ} \mathrm{C}$ before being reduced to approximately $27^{\circ} \mathrm{C}$. This was achieved simply by opening the enclosure door and deactivating the heating coils. After a period of 5 minutes, the enclosure door was closed, with the heating coils re-energised. The air temperature within the enclosure then returned to $63^{\circ} \mathrm{C}$ where it remained for a further 30 minutes before repeating the cool-down process. The air temperature then remained at this setpoint for a greater period (20 minutes) before increasing to the $43^{\circ} \mathrm{C}$ where it remained for 40 minutes, 
with a final repeat of the cool down process. During these fluctuations, the reference fluid temperature as measured by the VLFF PRTs was shown to remain stable.

Fig. 18. trends the test meter fluid density error throughout the test and shows a clear correlation with the sudden air temperature changes induced by cycling the enclosure.

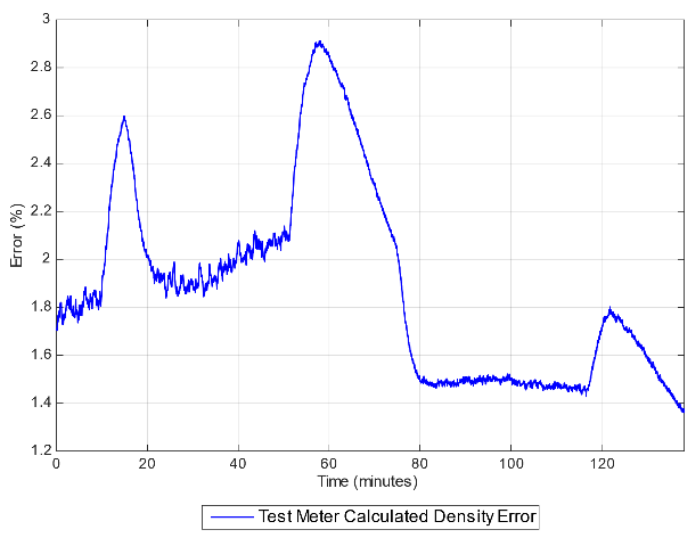

Fig. 18-Meter B test meter density error (Kerosene)

The errors shown in the above figure highlight that at the start of the test, the density output was already in error of $+1.8 \%$ due to the elevated test meter air temperature. During the longer periods of stable test meter air temperatures $\left(63^{\circ} \mathrm{C}\right.$ at 15 minutes and $43^{\circ} \mathrm{C}$ at 55 minutes), the error in meter output were $+2 \%$ and $+1.5 \%$ respectively. The errors are also shown to temporarily spike at the point of enclosure temperature setpoint change. This effect was also observed to a lesser extent in the data presented in sections 3 and 4.1. The authors note from personal experience that this spike is the result of a lag in the internal Coriolis meter temperature sensor response compared to the physical changes in Coriolis flow tube period (Young's modulus). To illustrate, Fig. 19. shows the generalised principles of temperature compensation used in Coriolis meter design.

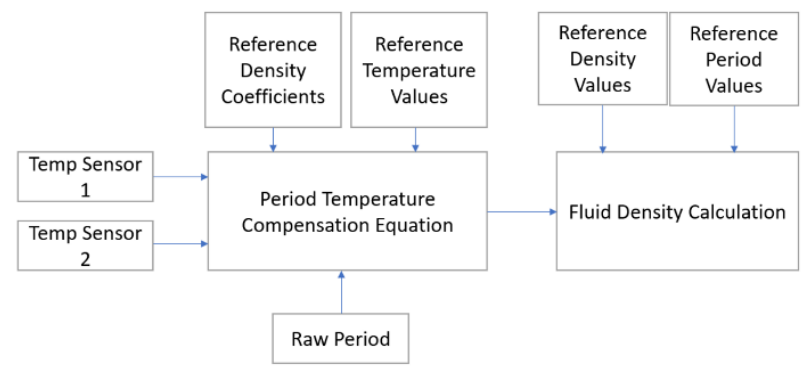

Fig. 19 - Genarilsed Coriolis raw period temperature compensation algorithm structure.

In practice, the coeffcients and reference values depicted in Fig. 19. are generated by the manufacturer using reference fluids (typically water and air). Regardless of the specifics in compensation equations, if the rate of process value change in both/either of the temperature sensors were to differ from the tube period rate of change, the model shown in Fig. 19., will perceive a thermal imbalance, and temporarily report a spike (in error) with either a positive of negative bias depending on which process value has the greater rate of change.

\section{DISCUSSION AND CONCLUSIONS}

The results presented here have demonstrated the potential for error in Coriolis meter calculated density. The errors were induced by ambient air temperature changes. Specifically, as the differential between the flowing fluid and test meter ambient air temperature increased, the error in both the uncompensated and compensated fluid density was shown to increase. These results combined with our preceeding research [9] indicate that limitations exist within the temperature compensation models tested. The errors observed are therefore likely to be incurred in the field under comparable conditions.

It is common practice for density calibration coefficients to be determined at the end of the meter manufacturing process using a reference fluid temperature of $20^{\circ} \mathrm{C}$, and water as the baseline fluid [4]. This research has shown that despite maintaining a fluid temperature close to $20^{\circ} \mathrm{C}$ throughout experimentation, the additional parameter of ambient air temperature remains unaccounted for in the models tested. Furthermore, it was shown that as the fluid properties deviated from that of water, the density values generated by Meter A contained greater errors.

It is clearly desirable, particularly in installations where the fluid properties are known to frequently change, for the meter to dynamically compensate for these effects without manual intervention. It is therefore suggested that further work in this area investigates the development of automatic compensation methods for the combined effects of ambient air temperature, fluid temperature and fluid properties.

The authors are aware of an emerging subset of Coriolis meter, which has been designed for use as a densitometer [18], [19]. This programme did not test such a device and instead focussed on standard Coriolis meter models, developed primarily for mass flow metering. It would, therefore, be interesting to repeat these experiments on the new densitometer device. In addition, thermal modelling, using the raw data collected during this research programme, would further validate the observed effects.

\section{REFERENCES}

[1] R.Baker,"Coriolis flowmeters: industrial practice and published information“, Flow Meas. Instrum. 5 (1994) 229-246.

[2] M. Anklin, W. Drahm, A. Rieder, "Coriolis mass flowmeters: overview of the current state of the art and Latest research, " Flow Meas. Instrum. 17 (2006) 317-323.

[3] T. Wang, R. Baker, Coriolis flowmeters: a review of developments over the past 20 years, and an assessment of the state of the art and likely future directions, Flow Meas. Instrum. 40 (2014) 99-123.

[4] ISO 10790:2015, Measurement of Fluid Flow in Closed Conduits - Guidance to the Selection, Installation and Use of Coriolis Meters (Mass Flow, Density and Volume Flow Measurement). 
[5] L. Wang, L. Hu, X. Fu, P. Ye, Experimental Investigation on Zero Drift Effect in Coriolis Mass Flowmeters, in FLOMEKO, Taipei, Taiwan, October 13$15,2010$.

[6] O. Øiestad, S. Fosse, S.Vervik, L. Falnes, Are Coriolis Mass meters suitable for Fiscal Liquid Applications? in North Sea Flow Measurement Workshop, Tønsberg, 2010.

[7] C. Marshall, Flow Meter Diagnostics - The Future of Measurement, South East Asia Flow Measurement Conference, 2013

[8] M. P. Henry, D. W. Clarke, N. Archer, J. Bowles, M. J. Leahy, R. P. Liu, J. Vignos, F. B. Zhou, A selfvalidating digital Coriolis mass-flow meter: an overview, Control Engineering Practice, 8 (2000) 487-506.

[9] G. Lindsay, J. Hay, N. Glen, S. Shariatipour, Profiling and Trending of Coriolis Meter Secondary Process Value Drift Due to Ambient Temperature Fluctuations, Flow Meas. Instrum, 59 (2018) 225-232.

[10] G. Lindsay, N. Glen, S. Shariatipour, and M. P. Henry, Detecting and Correcting for Coriolis Meter Calculated Fluid Density Drift due to Ambient Temperature Variation, in North Sea Flow Measurement Workshop, Aberdeen, 2018.

[11] G. Lindsay, Coriolis Density Error-Targeting Ambient Temperature Fluctuation and the Development of a New Temperature Compensation Model, in North Sea Flow Measurement Workshop, Tønsberg, 2019.

[12] M. Sadri, S. Shariatipour, A. Hunt, Effects of Flow Measurement Errors on Oil and Gas Production Forecasts, Computational \& Experimental Methods, in Multiphase \& Complex Flow, 9 (2017) 115-133.

[13] C. Marshall, M. Sadri, H. Hamdi, S. Shariatipour, S.M. Lee, A.L. Thomas, J.S. Stewart, The Role of Flow Measurement in Hydrocarbon Recovery Forecasting in the UKCS, Journal of Porous Media, 22 (2019) 957-973.

[14] M. Sadri, S. Shariatipour, A. Hunt, M. Ahmadinia Effect of systematic and random flow measurement errors on history matching: a case study on oil and wet gas reservoirs, Journal of Petroleum Exploration and Production Technology, 9 (2019) 2853-2862.

[15] Sadri, M., \& Shariatipour, S. M., (2020). Mitigating Allocation and Hydrocarbon Accounting Uncertainty Using More Frequent Flow Test Data. Journal of Energy Resources Technology.142 (4).

[16] Sadri, M., \& Shariatipour, S. M., (2020). Employing an artificial neural network to reduce the uncertainty in oil and gas production data. Journal of Energy Resources Technology (in press).

[17] G. Lindsay, Detecting and Correcting Calculated Fluid Density Errors in Coriolis Meters Due to Ambient Air Temperature Changes, Engineering Doctorate (EngD) thesis, Centre for Fluid and Complex Systems, Coventry University, 2019.

[18] Accurate custody transfer and batch measurement with Micro Motion density meters, Case Study, Ref no AN-001390 Rev B, Emerson Process Management, 2015.

[19] A. Rieder, P. Ceglia, New Generation Vibrating Tube Sensor for Density Measurement under Process Conditions, in North Sea Flow Measurement Workshop, Tønsberg, 2017. 